THURSDAY, MARCH 9, I87 I

\section{THE TEMPLE MEMORIAL AT RUGBY}

WE hear with peculiar satisfaction that one of the memorials of the Bishop of Exeter at Rugby is to be an Observatory. It is a very appropriate memorial to a man who, above most others, recognised the true relations of science and literature, and did so much to give science its rightful place. And it is a valuable addition to the resources of a school ; at present perhaps it will not find its full use; but when it does it will be well associated with the name of one who has foreseen the future position of our great public schools.

Our great public schools fulfil two functions, they prepare for the universities, but they are themselves the universities for the great majority of the boys who go to them ; those who go into business, into the army, and to many other occupations, do not in general go to Oxford or Cambridge. Their school education ends at eighteen. Now this large class is scarcely sufficiently contemplated at schools. For them it is necessary that a school should offer, not the first part of an education which requires many years to complete it, but the best education that can be given where this limit of age is imposed. For such boys as these it is highly desirable that their school course should have more elevation about it, and more of practical application. It would take us far from our present subject if we were fully to develop our meaning; but it seems a step, and an important one, in the right direction, to establish an astronomical and meteorological observatory at one of the public schools; for this is to assert that such knowledge of these subjects as is attainable ought to be within reach of boys who will not have the opportunity of studying them after complete mathematical training at the universities. It is one step further towards establishing the ideal education, the co-existence of religious influence, literature, science, art, and handicraft in the same institution.

Some amount of astronomical teaching is necessary in a school; it is very much neglected at present, because it does not pay in examinations. Yet we know by experience that few subjects are so interesting as astronomy. And in schools, as at Rugby, where geometry and mechanics are taught, the noblest illustrations may be taken from the mechanism of the heavens. But astronomy cannot be taught by a book only. The most useful, indispensable instrument to an astronomical teacher is an orrery. No descriptions, no diagrams, give boys a conception of the solar system so clearly as a few minutes with an orrery. The next most useful instrument is a telescope. And certainly Rugby seems to be fortunate in the instrument that is to be given to it.

The Temple Telescope is a noble one. The object-glass, of 81 in., was made with especial care and pains by Alvan Clarke for Mr. Dawes. It is 81 inches aperture, and 1083 focal length. It is mounted equatorially, has an excellent driving clock, of an unique kind; and the eyepieces range from 92 to 1,000 .

An instrument like this is, of course, a luxury, but its beauty is, in itself, a great inducement to its use. There are few things so wondrously beautiful as the moon,

VOL. III. or Jupiter, or a star cluster, seen with a low power in such a telescope. And any one who has tried to show the moon to several people with an ordinary telescope will appreciate the advantage of having it equatorially mounted, and of its being provided with a driving clock.

Other instruments for astronomy, surveying, and meteorology, will be added to the observatory; some of the masters having provided a fund adequate to give so fine an instrument all the surroundings that are required to make it practically available. And ere long we hope to see a really useful observatory established.

It is to be under the joint management of Mr. Wilson, who munificently gives the telescope, and Mr. Seabroke, an old Rugbeian, who is already favourably known as a worker. He still has his spurs to win, however, and will soon be very favourably situated for winning them.

The telescope is now the properity of the Rev. H. E. Lowe, of Atherstone, but will become the property of Mr. Wilson in March. We greatly regret to hear that circumstances which have lately happened at Rugby affecting the tenure of masterships will prevent for the present the gift of the observatory to the school, and can only hope that it will not be long before the present difficulties are overcome. Meantime it will be established on private ground, and will be accessible to the school. Verily there be head-masters and head-masters, and masters and masters !

\section{THE EXPERIMENTAL AND NATURAL SCIENCES IN TRINITY COLLEGE, DUBLIN}

THE condition of the Experimental and Natural 1 Sciences in the various Universities is at the present time a subject of such general interest that we give the following sketch of what is now done for them in Trinity College, Dublin.

Until a student passes the Michaelmas term examination of his second (Senior Freshman) year he is supposed to confine his attention to classics, mathematics, and logic ; but in his third and fourth years he must devote himself, to a certain extent, to the study of Experimental Physics, including heat, electricity, magnetism, and chemistry, and pass examinations on these subjects even at the ordinary term examinations. In the fourth year of his studies the student can go in for honours in Natural and Experimental Sciences, the course for which includes Jamin's "Cours de Physique," Lloyd's "Wave Theory of Light," Naquet's "Principles of Chemistry," Cotta's "Classification of Rocks," and Haughton's "Manual of Geology."

At the conclusion of his collegiate studies the student can graduate in either Experimental or in Natural Science, and the Court of Examiners can recommend the most distinguished of the candidates to the Board for gold and silver medals; candidates thus recommended receiving their B.A. degrees as Senior and Junior Moderators respectively.

The subjects for examination for the Moderatorships in Experimental Science are (I) Experimental Physics viz., Heat, Light, Sound, Electricity, and Magnetism ; (2) Chemistry, Inorganic and Organic ; (3) Mineralogy, including Crystallography; and the hundred marks allotted to the examination are as follows:-Light and 
Sound, 20; Heat, Electricity, and Magnetism, ̧̧०; Irrorganic and Organic Chemistry, I5 each; Mineralogy and Crystallography, Io each. It need only be added that lectures on all these subjects are delivered every term by the respective Professors.

The subjects of examination for the Moderatorship in Natural Science are the following, each of which has equal weight:-(I) Physiological ard Comparative Anatomy ; (2) Zoology and Botany; (3) Geology (including Physical Geography and Palæontology).

It may be objected that the distinction between Zoology and Comparative Anatomy will not hold good, and the books ordered to be read under both sections seem to demonstrate this. But there can be little doubt that the establishment of this Moderatorship is a step in the right direction, and the course is such that every medical student ought to take it up and do his utmost to attain a place among the golds.

It is of course not to be denied that there are no scholarships, no studentships nor fellowships to be attained by a knowledge of these sciences, but perhaps even these may in time come. It is not so very long ago when a student could aspire to but few distinctions if he were not a first-rate mathematician; now this is completely altered, and as the world rolls on changes come with it.

The chemical and physical laboratories of the College leave nothing to be desired. The distinguished Medical Registrar takes care that there shall be every facility given to students to work out the Comparative Anatomy of the Vertebrates, and places at the disposal of the College the animals that from time to time die in the Zoological Gardens. The Professor of Zoology demonstrates the Anatomy of the Invertebrates to his class during two out of the three terms. The Botanical Gardens and the Herbarium are as extensive as any University can require, and there are two courses, one of forty and another of twenty lectures, delivered each year in Botany, besides garden demonstrations.

In conclusion we venture to suggest that if the M.D. degree should only be taken by the reading and publishing of a Thesis, as in some of the German Universities, it would help materially to assist the cause of the Sciences in Trinity College, Dublin; for, though some of the candidates might select practical subjects, others, doubtless, would turn their attention to the wide fields of Zoology and Botany. W.

\section{SIR FOHN LUBBOCK ON THE ORIGIN OF CIVILISATION}

The Origin of Civilisation and the Primitive Condition of Man : Mental and Social Condition of Savages. By Sir John Lubbock, Bart., M.P., F.R.S., \&c. (Longmans, 1870.)

NOW that Sir John Lubbock's work on" the "Origin of Civilisation" has reached a second edition, it is perhaps only natural that those who make it their business to warn the public against the encroachments of Science should raise an alarm against the first. In a recent number of the Christian Advocate and Review appears, accordingly, an article specially devoted to the demolition of Sir John's theories, and the vindication of human degeneracy. With the felicitous instinct of clerical anta- gonism, the Advocate and Reviewer makes his fiercest onslaught precisely where his opponent happens to be least vulnerable, and lays about him with all the fine, fervid imbecility distingtive of his particular clique. Such an attack, however, were ignorance its only characteristic, would hardly call for remark. We notice it, not for its absurdity, but because, in combining with its absurdity a certain unctuous disingenuousness, it is really a typical example of a kind of criticism unhappily influential, if obscure, and widely accepted, if not popular. It would perhaps be too much to expect that reviewers of this class should read through the books they review, but at least they have no right to misquote what they do read. On p. 256 (first edition), Sir John Lubbock, speaking of errors into which, in the absence of education, not even Christianity prevented mankind from falling, writes thus : "We know that a belief in witchcraft was all but universal until recently even in our own country. This dark superstition has indeed flourished for centuries in Christian countries, and has only been expelled at length by the light of science." He then proceeds to observe: "The immense service which science has thus rendered to the cause of religion and humanity, has not hitherto received the recognition which it deserved." His reviewer, omitting any reference to witchcraft, quotes Sir John as asserting that "the immense service which Science has rendered to the cause of religion and humanity, has not hitherto received the recognition it deserves"-a proposition which may or may not be accurate, but is certainly not the one laid down by Sir John Lubbock. But he is not content with merely misrepresenting the book under review. Sir John Lubbock, he correctly remarks, at Liverpool, "frankly avowed 'there was no opposition between science and religion,' an admission," he adds, "of no slight importance by so great an authority in the scientific world, as it is such a quiet reouff to the boast of Bishop Colenso, that the differences between these two are such as to render it hopeless to attempt their reconciliation." If, however, we are bewildered at the brisk audacity which could venture on such a statement without even a hint at its wholly fabulous character, what are we to say to a critic who gravely asserts that "the Drift age had not been invented at the time" when Sir Charles Lyell wrote his "Geological Evidence of the Antiquity of Man"? and who assigns to the "prehistoric period in Sweden a minimum antiquity of 20,000 , or it may be of $20,000,000$ years."

But enough of the Christian Advocate. Turn we now to other and nobler opponents. The conclusions main. tained by Sir J. Lubbock in this work are, in his own words-

"That existing savages are not the descendants of civilised ancestors.

"That the primitive condition of man was one of utter barbarism.

"That from this condition, several races have independently raised themselves."

On the other hand, we have the opinion of the late Archbishop Whately, that "We have no reason to suppose that any community ever did or ever can emerge, unassisted by external helps, from a state of utter barbarism into anything that can be called civilisation ;" and that of the Duke of Argyll, who holds that the primitive zondition of man was one of civilisation; that "there is 